\title{
VEGF-Directed Blood Vessel Patterning: From Cells to Organism
}

\author{
Victoria L. Bautch \\ Department of Biology, Lineberger Comprehensive Cancer Center, McAllister Heart Institute, \\ The University of North Carolina at Chapel Hill, Chapel Hill, North Carolina 27599 \\ Correspondence: bautch@med.unc.edu
}

VEGF-A signaling is required for almost every aspect of vascular development, and it is a major regulator of vessel morphogenesis and patterning. VEGF-A perturbations are associated with severe vascular defects and lethality, and the pathway is coopted in pathological scenarios, including tumor angiogenesis. This review focuses on the roles of VEGF-A signaling during vessel development and patterning. I review the impact of VEGF-A signaling on endothelial cells in developing vessels, with emphasis on the importance of spatial regulation of several pathway components. I also discuss VEGF-A signaling patterns at the level of the vessel, with a focus on how polarity is set up and maintained in several vessel axes. The role of VEGF-A in patterning vessels relative to tissues and organs is also reviewed, with emphasis on neurovascular patterning and patterning at the embryonic midline.

$V$ EGF-A (vascular endothelial growth factor, VEGF) is important for almost every aspect of blood vessel formation and function. VEGF-A is required developmentally for the differentiation and/or expansion of angioblasts, the major precursor of endothelial cells. It is critical for the survival of endothelial cells, and the angiogenic expansion of primitive vessels via sprouting requires VEGF-A signaling. It also regulates barrier function in mature vessels. Other members of the VEGF family have roles in lymphangiogenesis and/or in pathological angiogenesis. My goal is to focus on the role of VEGF-A (VEGF) in blood vessel patterning and network formation. Thus, I will briefly outline the VEGF proteins and receptors that are relevant to vessel patterning, then discuss how VEGF patterns vessels at three levels-that of the cell, the vessel, and the tissue/organism. The cellular effects of VEGF on vessel development cover spatial heterogeneity in VEGF presentation and signaling, the role of the VEGF receptor Flt-1, and the role of VEGF isoforms and matrix in this process. The mechanisms used by the VEGF pathway are compared and contrasted with other pathways that regulate morphogenesis in other developing models. At the level of the vessel, the polarity of vascular endothelial cells that is required for lumen formation, the polarization to shear stress, and the polarization of endothelial divisions to affect vessel shape are discussed. Next, how VEGF signaling is used to set up patterning at the level of tissues and organisms is covered, with a focus on midline and neural tube patterning. Finally, I discuss some outstanding

Editors: Michael Klagsbrun and Patricia D'Amore

Additional Perspectives on Angiogenesis available at www.perspectivesinmedicine.org

Copyright (C) 2012 Cold Spring Harbor Laboratory Press; all rights reserved; doi: 10.1101/cshperspect.a006452

Cite this article as Cold Spring Harb Perspect Med 2012;2:a006452 
V.L. Bautch

questions related to VEGF-induced vessel patterning and highlight how current research will lead to a better understanding of how VEGF signaling is regulated, and why this regulation is important therapeutically.

\section{GENERAL DESCRIPTION OF VEGF EFFECTS ON VESSELS}

VEGF signaling is critical to the expansion of angioblasts that coalesce to form the initial vessels, such as the dorsal aorta, via vasculogenesis (for reviews, see Risau 1997; Cleaver and Krieg 1999; Coultas et al. 2005). It is also required for subsequent endothelial cell sprouting migration that leads to the expansion and patterning of the vessel network via angiogenesis. The primary ligand in vessel expansion and patterning is VEGF-A (referred to as VEGF in this review), and genetic deletion of even one copy of VEGF-A is embryonic-lethal because of lack of vessel development, suggesting that VEGF regulates vascular processes within a relatively narrow range of ligand concentration (Carmeliet et al. 1996; Ferrara et al. 1996). This quantitative regulation is accompanied by spatial regulation of VEGF-A presentation to nascent vessels via alternative splicing of VEGF-A to yield three major isoforms with different affinities for the extracellular matrix (Park et al. 1993).

VEGF-A interacts with two high-affinity receptors, VEGFR-2 (Flk-1, KDR) and VEGFR-1 (Flt-1). VEGF binding to VEGFR-2/Flk-1 stimulates endothelial cell proliferation, migration, and survival; and genetic loss of $f l k-1$ in mice leads to embryonic lethality with loss of vessel development (Shalaby et al. 1995). Genetic loss of flt-1 also leads to embryonic lethality, but with vessel overgrowth and dysmorphogenesis (Fong et al. 1995). This phenotype results from increased endothelial cell proliferation and elevated signaling through VEGFR-2, suggesting that VEGFR-1 acts to negatively modulate VEGF signaling during development (Kearney et al. 2002; Roberts et al. 2004). Neuropilin coreceptors interact with the VEGF receptors to positively modulate signaling (Soker et al. 1998; Whitaker et al. 2001), and genetic loss of Neuropilin-1 results in vascular migration defects, with poorly branched and dilated vessels leading to lethality (Kawasaki et al. 1999; Gu et al. 2003).

\section{EFFECTS OF VEGF ON ENDOTHELIAL CELLS IN DEVELOPING VESSELS}

Evidence that VEGF signaling is spatially regulated came from the identification of alternatively spliced isoforms as described in the previous section-the major VEGF isoforms (Fig. 1A) result from splicing that removes one or two exons with heparin-binding matrixinteraction domains, such that VEGF121 is predicted to be more diffusible, VEGF165 less diffusible, and VEGF189 to have the strongest matrix interactions and be the least diffusible (for review, see Ferrara 2010). This suggests that expression of all three isoforms from a tissue expressing VEGF sets up a gradient, with the highest concentration of ligand closest to the source (Fig. 2). Physical evidence for gradients in vivo is difficult to obtain, but antibody staining suggests such a VEGF gradient in the developing hindbrain (Ruhrberg et al. 2002). Moreover, expression of only the VEGF120 isoform (mouse VEGF isoforms have one less amino acid than the human versions) in developing mouse embryos leads to dilated and poorly branched vessels along with lethality, whereas expression of only the heparin-binding VEGF188 isoform leads to thin and overly branched vessels (Ruhrberg et al. 2002; Stalmans et al. 2002). These genetic data strongly indicate that regulated spatial VEGF presentation is important for proper vessel morphogenesis. One model that explains these results is that a proper VEGF gradient is necessary to stimulate sprouting and branching, whereas overall VEGF levels regulate endothelial proliferation. The relative amount of proliferation versus sprouting is important for network formation, and loss of this integration leads to proliferation in the absence of sprouting (VEGF120/120 mice) or excessive sprouting relative to proliferation (VEGF188/188 mice) and aberrant morphogenesis. This model is reinforced by the finding that tumor expression of a VEGF-A 

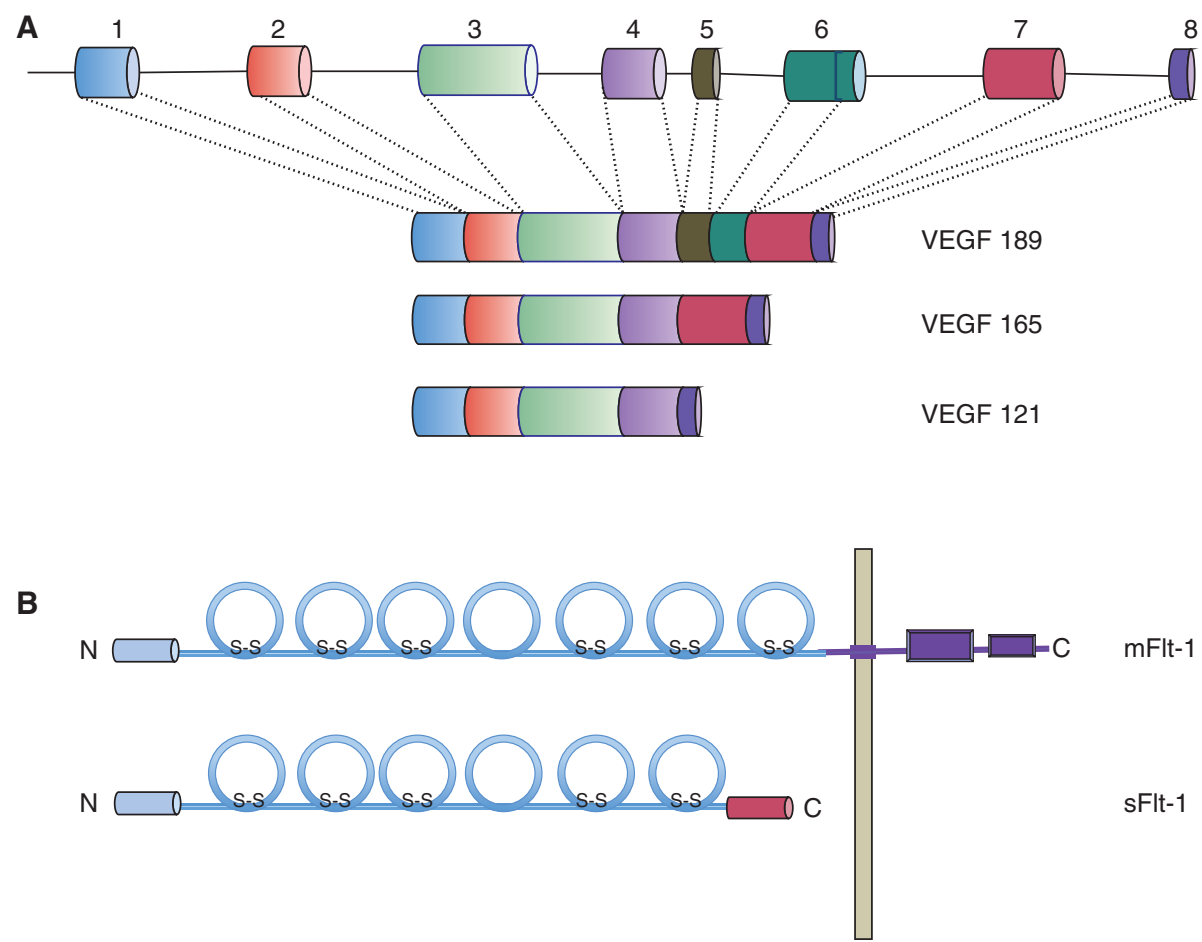

Figure 1. Alternative splicing of VEGF-A and VEGFR-1 (Flt-1) leads to distinct isoforms. (A) Alternative splicing of the initial transcript from the VEGF-A locus leads to three major VEGF-A isoforms (minor isoforms not shown): VEGF121, VEGF165, and VEGF189 (in mouse, VEGF120, VEGF164, and VEGF188). Exons 6 and 7 have heparin-binding domains, thus each major isoform has a different capacity for matrix interactions. (B) Alternative splicing of VEGFR-1 (Flt-1) leads to the two protein isoforms shown here. mFlt-1 is membrane-tethered, whereas sFlt-1 is secreted from the cell. Both Flt- 1 isoforms have heparin-binding capability. Blue sections are shared by both isoforms, the red section is specific to sFlt-1, and purple sections are specific to mFlt-1.

protein that cannot be proteolytically cleaved and released from the matrix results in thin, highly branched vessels, whereas similar expression of a cleaved version of VEGF-A leads to dilated tumor vessels (Lee et al. 2005). Recent data also indicate that matrix-bound VEGF stimulates sustained signaling through VEGFR-2 and activation of downstream pathways distinct from those activated by soluble VEGF, suggesting how proliferation and branching might be integrated via a VEGF gradient (Chen et al. 2010). Finally, endothelial cells themselves express low levels of VEGF that contribute to vessel homeostasis, and perhaps also to sprouting migration via integrin regulation of VEGFR-2 (Lee et al. 2007; da Silva et al. 2010). Taken together, these data highlight that VEGF-A presentation is important for proper vessel morphogenesis and is controlled by several mechanisms that spatially regulate ligand availability.

Several years ago, the concept of "tip" cell and "stalk" cell phenotypes was described for emerging sprouts (Gerhardt et al. 2003). Briefly, the tip cell is the leading cell of a sprout that presumably experiences higher levels of VEGF signaling, whereas the cells behind the tip cell are stalk cells that likely experience lower levels of VEGF signaling, and this difference is maintained by interactions of the VEGF pathway with the Notch-Delta pathway (Hellstrom et al. 2007; Lobov et al. 2007; Suchting et al. 2007; Siekmann et al. 2008). It is essential that forming vessel networks have a distribution of 
V.L. Bautch

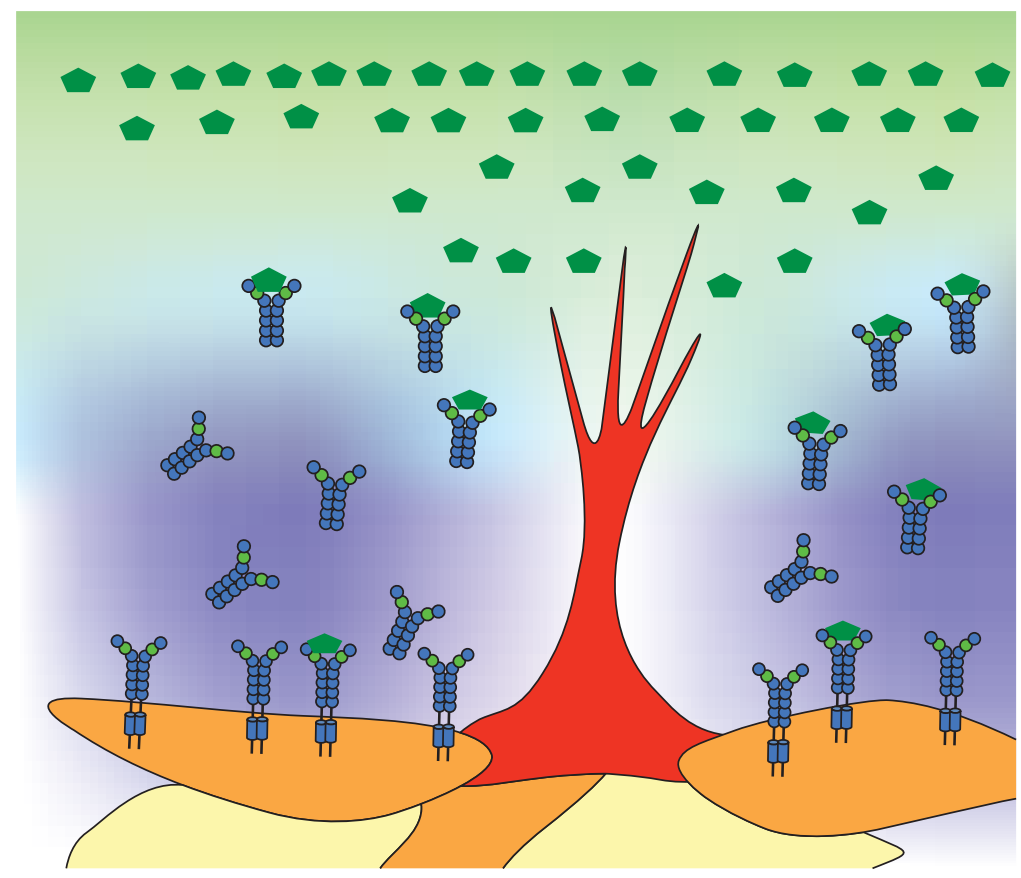

Figure 2. Model of spatial organization of VEGF-A signaling components. VEGF-A is released from a source ( $t o p$ of figure) and, owing to isoform-specific differences in matrix interactions, forms a gradient (green areas) from the source to the target vessel. Some endothelial cells respond to this signal by acquiring a tip cell (red cell) identity and migrating up the gradient, whereas adjacent lateral base cells (orange cells) up-regulate Flt-1 (VEGFR-1) and secrete soluble Flt-1 (blue areas) that inactivates VEGF-A in the lateral areas, providing a corridor of ligand for effective outward migration of the sprout. (Green icons) VEGF-A protein; (blue receptors) membranelocalized and soluble Flt-1.

tip and stalk cells—-too many tip cells leads to poor vessel perfusion, whereas too many stalk cells results in poorly arborized networks. Other articles in this collection discuss this paradigm more comprehensively; however, it is important to note that spatial differences in VEGF signaling are critical to these phenotypic changesendothelial cells that experience higher levels of VEGF signaling are preferentially found at the tip position in competition experiments (Jakobsson et al. 2010).

The VEGF receptor Flt-1 (VEGFR-1) is alternatively spliced to produce soluble (sFlt-1) and membrane-localized (mFlt-1) isoforms (Fig. 1B) (Kendall and Thomas 1993), and the differential effects of these isoforms on vessel patterning suggest that VEGF signaling is spatially regulated by localized Flt-1 expression (Kappas et al. 2008; Chappell et al. 2009).
Both Flt-1 isoforms bind VEGF-A with higher affinity than does Flk-1 (Park et al. 1994), and they can function as competitive inhibitors of the pathway via ligand binding. Negative modulation of VEGF signaling is likely the predominant mechanism whereby Flt-1 regulates developmental angiogenesis, because mice lacking the Flt-1 cytoplasmic domain required for signaling are viable (Hiratsuka et al. 1998). Genetic rescue of flt-1 mutant vessels with mFlt-1 rescues only proliferation defects, whereas rescue with sFlt-1 rescues both proliferation and branching defects, indicating that the Flt-1 isoforms differentially affect vessel proliferation versus sprouting (Kappas et al. 2008). Because sFlt- 1 is secreted from endothelial cells, this moiety can bind and potentially inactivate VEGF at a distance from the producing cell. Flt-1 has heparin-binding properties (Park 
VEGF-Directed Blood Vessel Patterning

and Lee 1999), suggesting that it can form a gradient into the matrix from its source, the developing vessel. We recently proposed a model whereby initial stochastic differences in sFlt-1 production by individual endothelial cells of a developing vessel result in increased expression of sFlt- 1 by cells adjacent to an emerging sprout, and this expression is proposed to provide localized VEGF inactivation and thus more active ligand in the area immediately ahead of the migrating sprout (Fig. 2) (Chappell et al. 2009). Evidence for this model of Flt-1-dependent local sprout guidance is that vessels lacking flt -1 have misguided sprouts, and mosaic analysis reveals a requirement for sFlt- 1 in endothelial cells immediately adjacent to the sprout for proper sprout guidance.

There are several parallels between VEGF signaling and other pathways that influence developmental morphogenesis. Numerous signaling pathways important in development are thought to act via gradients, including Wnt, Dpp, and Shh (for review, see Ashe and Briscoe 2006). These gradients are regulated in complex ways. For example, the Wnt receptor Frizzled also has soluble forms, although they are produced by distinct genetic loci (Bovolenta et al. 2008). Soluble Frizzled-related proteins (sFRP) are proposed to influence Wnt signaling in several ways, including acting as antagonists or paradoxically acting to diffuse the Wnt ligand (Mii and Taira 2009). There are also other negative regulators of Wnt/Wg signaling that are instigated by the signaling cascade and modify the interpretation of the gradient. One example is notum (also called wingful), a gene encoding a secreted phospholipase that potently inhibits Wg signaling that is expressed in cells adjacent to Wg-producing cells at the D-V midline (Piddini and Vincent 2009). Likewise, a complex regulatory loop that includes both positive and negative regulators induced by Shh signaling modifies the initial Shh signal that patterns the vertebrate neural tube in the D-V axis (for review, see Ribes and Briscoe 2009). Finally, similar to the VEGF ligand, numerous secreted morphogens (i.e., Wnt, $\mathrm{Hh}$, and BMP) interact with heparan sulfate proteoglycans to control morphogen movement and signaling (for review, see Yan and Lin 2009).

\section{HOW VEGF PATTERNS NASCENT BLOOD VESSELS}

VEGF signaling is also important developmentally for the coordinated responses of endothelial cells that result in polarized and lumenized vessels (for reviews, see IruelaArispe and Davis 2009; Ellertsdottir et al. 2010; Zeeb et al. 2010). Endothelial cells in vessels polarize in several planes (Fig. 3). Early in development, endothelial cells distinguish the surface that faces inward toward other

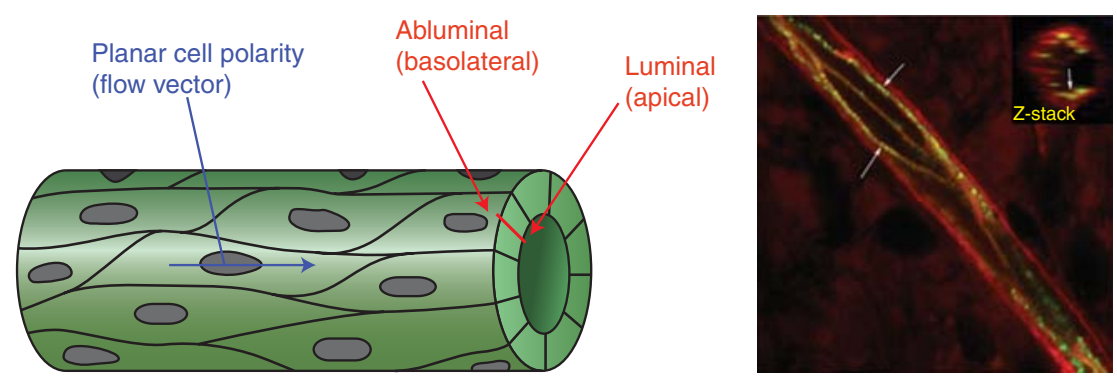

Figure 3. Blood vessel polarity. Blood vessels polarize in the apical (luminal) versus basolateral (abluminal) planes, and in the plane of the tube (planar cell polarity). (Right panel) The mouse P5 retinal vessel stained with isolectin B4 (red) after perfusion fixation with the same lectin (labeled in green). Arrows point to membranes that have both labels and are likely to be the apical surfaces, and the inset in the upper right shows a $Z$-stack projection. 
V.L. Bautch

endothelial cells (luminal or apical) from the surface that faces outward toward the extracellular matrix/basement membrane (abluminal or basolateral) (Fig. 3). The luminal side is the eventual site of lumen formation, and new lumens connect to more mature lumens with blood flow. Endothelial cells subsequently orient in the plane of the vessel (planar cell polarity) in response to shear stress provided by blood flow, at least in large conduit vessels (for review, see McCue et al. 2004). Finally, they also orient their spindles as they divide, and in developing vessel networks this orientation puts the cleavage plane perpendicular to the vessel long axis and extends the length of the vessel (Zeng et al. 2007).

The first polarization of a nascent vessel is the apical/basolateral polarization that is required for regulated endothelial transcytosis and lumen formation. It has been relatively difficult to localize polarity complexes that are predicted to be apical or basolateral in endothelial cells, in part, because normal endothelial cell shape places the apical surface close to the basolateral surface, and there is little depth to the lateral surface. A recent study investigated the forming dorsal aorta in early mouse embryos (Strilic et al. 2009). They found that apical markers localize to the inner surfaces of the endothelial cells before lumen formation, and loss of junctions or acto-myosin contractility perturbed this process. They provided evidence that lumen formation involves apical polarization of sialomucins that prevent junctional contact, and that subsequent cell shape changes produce the lumen. Interestingly, genetic loss of Vegfa resulted in lack of lumen formation. Cell-based data suggested that VEGF signaling is upstream of Rho kinase and non-muscle myosin-induced cell shape changes, but polarization per se was not affected by loss of Vegfa. This model of lumenization is consistent with the concept that apical-basolateral polarization is a prerequisite for lumen formation, perhaps because of a requirement for polarized trafficking of specific molecules and/or vesicles, and that VEGF-influenced events subsequent to polarization are also important. In other vessel beds, there is polarized trafficking of vesicles or vacuoles to specific cell surfaces and/or the middle of cells to instigate lumen formation (Kamei et al. 2006; Blum et al. 2008).

The basolateral side of the endothelial cell provides information for polarization to developing vessels. Basolateral areas interact with extracellular matrix, and integrin signaling via binding sites in the ECM contributes to the establishment of polarity. Genetic deletion of $\beta 1$ integrin has been particularly informative, perhaps because several endothelial integrin heterodimers (i.e., $\alpha 1, \alpha 2 \alpha 3, \alpha 4, \alpha 5, \alpha 6, \alpha \mathrm{v}$ heterodimers with $\beta 1$ ) are affected by loss of $\beta 1$ integrin. Several studies showed that $\beta 1$ loss in endothelial cells results in aberrant endothelial adhesion and migration, and consequent defects in angiogenesis and embryonic lethality (Tanjore et al. 2007; Carlson et al. 2008). Zovein et al. (2010) specifically investigated effects of endothelial $\beta 1$ loss on apical-basolateral polarity and reported that arteries are selectively affected. Endothelial cells lacking $\beta 1$ integrin did not form proper basolateral connections, but entered and occluded the lumen. The polarity protein Par3 appears to be an effector of the phenotype, because Par3 levels were reduced with loss of $\beta 1$, and Par3 expression partially rescued the lumen phenotype (Zovein et al. 2010).

Once basolateral polarity is set up and lumens form and interconnect, blood flow commences, and the endothelial cells of conduit vessels orient in the plane set up by the long axis of the cells, which is called planar cell polarity. This orientation is seen in culture when cells are subjected to shear stress produced by flow, and it results in the orientation of the microtubule-organizing center (MTOC) and the Golgi downstream from the flow vector. This flow orientation requires transduction of mechanical cues, and it is thought that several complexes contribute to flow-mediated mechanotransduction (for review, see Hahn and Schwartz 2009). Among these are a complex that includes the VEGF receptor VEGFR-2 (Flk-1), PECAM-1, and VE-cadherin, although VEGF itself does not appear to be involved in the signaling (Tzima et al. 2005). 
Although most of the effects of shear stress on endothelial cells have been deduced from in vitro models, this polarization is clearly medically relevant in vivo because areas of disturbed flow are the sites of inflammatory signaling and atherosclerotic plaque development. Endothelial cells in vessel areas exposed to laminar flow orient their MTOC relative to the nucleus and the flow vector, although the actual orientation of the MTOC relative to flow is not always downstream but varies depending on the vascular bed. Endothelial cells also orient cell divisions with the cleavage plane perpendicular to the direction of flow in high-flow vessels such as the carotid artery (McCue et al. 2006). However, oriented endothelial divisions appear to be flow independent and VEGF dependent at early developmental stages. Embryonic stem cell-derived vessels that do not experience flow orient endothelial cell divisions with the cleavage plane perpendicular to the vessel long axis, and retinal vessels near the vascular front that likely have low shear stress also orient endothelial divisions, perhaps in order to extend vessel length in expanding vascular networks (Zeng et al. 2007). Elevated VEGF signaling due to loss of the negative modulator VEGFR-1 (Flt-1) results in randomization of endothelial division orientation, although expression of only the VEGF120 isoform does not significantly randomize endothelial division orientation in developing retinas (Zeng et al. 2007; SM Taylor, H Park, G Zeng, et al., unpubl.).

Finally, as vessels form and expand, mural cells are found associated with the basolateral side of endothelial cells. Virtually all vessels are invested with pericytes, and larger vessels also become covered with smooth muscle cells, and sometimes with fibroblasts (for reviews, see Holderfield and Hughes 2008; Gaengel et al. 2009; Kutcher and Herman 2009). Pericyteendothelial interactions are an area of active study, and although the effects of these interactions have not been directly linked to intrinsic endothelial cell polarity, coculture shows that basolateral basement membrane deposition does not occur when pericytes are absent (Davis 2010). This basement membrane interacts with the basolateral endothelial surface once deposited, and integrin interactions are likely important, although endothelial loss of $\beta 1$ integrin did not prevent pericyte-endothelial interactions (Zovein et al. 2010). Several signals, including VEGF-A and the Tie ligand Ang-1 (Darland et al. 2003), are secreted from pericytes and thus are predicted to be polarized basolaterally. Another pericyte-endothelial molecular interaction uses $\mathrm{N}$-cadherin, and $\mathrm{N}$-cadherin becomes localized to the basolateral surface between pericytes and endothelial cells (Paik et al. 2004). Much work remains to elucidate exactly how pericyte-endothelial interactions influence endothelial cell and vessel polarity, and the role of VEGF signaling in these processes.

Blood vessel formation has most often been compared with the formation of other epithelial tubes. For example, both the paradigm of tip cell versus stalk cell (Gerhardt et al. 2003) and the idea that cells compete with each other for the tip cell position in developing vessels (Jakobsson et al. 2010) are informed by seminal studies of the Drosophila tracheal system (Samakovlis et al. 1996; Ghabrial et al. 2003). Several modes of lumenization are proposed to occur during tracheal development (Lubarsky and Krasnow 2003), and some of these are now proposed for lumenization of developing vessels. It should be noted, however, that there are differences in the developmental programs. For example, the fly trachea forms from cells that do not divide as they migrate and undergo morphogenesis, whereas most vascular beds expand via endothelial cell divisions that accompany morphogenesis. The selection of tip versus stalk cell in the fly trachea sets up a difference in cell fates, yet in the developing vascular system, this distinction appears to be a phenotype as opposed to a fate, and tip cells can revert to stalk cells via mechanisms that are currently not well understood. Finally, the trachea is a conduit for air, which is a gas that brings oxygen to tissues, whereas vessels are conduits for blood, a liquid that imparts shear stress as it flows through vessels. Thus some of the mechanisms for vessel patterning and VEGF function are likely to be unique to developing vessels. 
V.L. Bautch

\section{VEGF PATTERNING AT THE LEVEL OF TISSUE/ORGANISM}

VEGF signaling is important for overall vessel patterning during development, as tissues and organs develop and the major body axes are set up. Seminal studies in the frog showed that angioblasts migrate medially from the lateral plate mesoderm toward the midline in response to a VEGF cue, where they assemble to form the dorsal aorta (Cleaver and Krieg 1999). In frogs and zebrafish, VEGF is produced by a transient midline structure called the hypochord. In avians and mammals, the dorsal aorta first forms as bilaterally symmetrical vessels in the trunk region, and these vessels then fuse to form a single tube between the forelimb and hindlimb areas on the anterior-posterior axis (for review, see Hogan and Bautch 2004). How the initial vessels are formed is not entirely clear, but angioblasts first appear in areas where the vessels will form, then they assemble into a cord. VEGF-A is produced by endoderm that lies along the midline below the nascent vessels, and one hypothesis is that endoderm-derived VEGF-A provides a positive midline signal for vessel patterning in avians and mammals. However, positive signaling is not sufficient for proper patterning of the dorsal aorta, and another midline structure called the notochord appears to provide negative cues for dorsal aorta patterning. The notochord expresses inhibitors of BMP signaling such as chordin, and developmentally regulated loss of chordin expression from the avian notochord correlates with fusion of the dorsal aorta (Reese et al. 2004; Garriock et al. 2010).

VEGF-A expression is dynamic during subsequent development, and VEGF is involved in both long-range and short-range signaling that influences vessel patterning. In general, VEGF expression is up-regulated in response to tissue hypoxia mediated through the HIF (hypoxia inducible factor) family of transcription factors, although the initial development of vessels early in development is HIF independent (for review, see Simon and Keith 2008). The neural tube straddles the midline dorsally, and it requires vascularization by recruitment of vessels because it does not contain angioblasts or endothelial cells (for reviews, see Mancuso et al. 2008; Bautch and James 2009). A long-range signal from the neural tube induces the migration of angioblasts and/or endothelial cells from lateral plate and laterally positioned somites to form a plexus surrounding the neural tube, called the PNVP (peri-neural vascular plexus) (Pardanaud et al. 1996; Ambler et al. 2001). Grafts genetically deleted for $f l k-1$ do not migrate toward the neural tube (Ambler et al. 2003), and neural-tube-derived VEGF-A is required for patterning of somite-derived vessels in cocultures (Hogan et al. 2004), suggesting that VEGF-A can act as a long-range signal for vascular plexus formation in development. Once the PNVP forms, neural-tube-derived VEGF-A acts at a shorter range to induce ingression of vessels sprouts into the developing neural tube (James et al. 2009). However, the stereotypical patterning of neural tube vessel ingression likely also involves negative cues because the VEGF-A expression domain is broader than the vessel ingression points. Moreover, additional attractive signals probably cooperate with VEGF in neural tube vessel ingression, because neural tubes lacking Wnt $7 \mathrm{a} / \mathrm{b}$ or the orphan Gprotein-coupled receptor GPR124 also have defective vessel ingression (Stenman et al. 2008; Daneman et al. 2009; Kuhnert et al. 2010).

VEGF is involved in vessel patterning in other tissues and organs and likely also acts in conjunction with other signals at these sites. For example, in the developing retina, a gradient of VEGF-A is proposed to emanate from the distal area and induce the proximal-distal migration of vessels from the area of the optic nerve outward (for reviews, see Dorrell and Friedlander 2006; Fruttiger 2007). The vessels also migrate on an astrocyte network that is laid down before vessel migration; although astrocytes produce VEGF-A, this expression is not required for the astrocyte-endothelial cross talk involved in vessel patterning because astrocyte-specific deletion of VEGF-A has only minor effects on vessel patterning but dramatically affects vessel stabilization (Scott et al. 2010). Nerves and arteries also follow each other 
in developing skin, and although nerve-derived VEGF-A is important for arterial specification of the vessels, it does not seem to provide direct patterning cues to the vessels in this context (Mukouyama et al. 2002, 2005).

Finally, VEGF is important for patterning of vessel networks that form without migrating toward an obvious source of VEGF. An example of this type of vessel patterning is found in the developing murine yolk sac, where VEGF-A is produced from the endoderm that underlies the mesoderm and also from mesoderm that gives rise to yolk sac vessels. Endoderm-derived VEGF is required for yolk sac vessel development and patterning, because mosaic loss of endoderm VEGF-A prevents vessel formation in the mesoderm above the mutant endoderm (Damert et al. 2002). Yolk sac vessels have an initial phase of sprouting angiogenesis and expand in the lateral plane, then the network undergoes extensive remodeling once blood flow commences (for review, see Culver and Dickinson 2010). It is interesting to speculate that vessel-derived negative cues, such as sFlt-1, may shape VEGF presentation to provide vessel-patterning cues in the lateral plane of the developing yolk sac.

\section{CONCLUSIONS AND PERSPECTIVES}

The last several years have provided important information regarding specific mechanisms whereby a single signaling pathway, instigated by the VEGF-A ligand, can influence and pattern vessels at several scales, from cell to organism. We also better understand how VEGF signaling intersects with numerous other important signaling pathways, such as NotchDelta and BMP, to modulate vessel development. We now appreciate that the spatial context of both the signals and the negative modulator Flt-1 is critical for proper patterning. We are beginning to understand how VEGF signaling influences polarity and other group behaviors of endothelial cells. Finally, we realize that VEGF is a critical component of the cross talk that is necessary between developing organs and tissues in an embryo and the vessels that provide nourishment, and we anticipate that intersection with other pathways is also important for this role of VEGF.

There is still much to be learned. We understand that localization of VEGF pathway components spatially is important, but we have not yet developed the ability to interrogate signaling in vivo using in situ probes. The evidence for VEGF gradients is indirect, and we are lacking essential knowledge of how VEGF gradients are set up, maintained, and interpreted. There is a strong interest in modeling aspects of VEGF signaling and interactions with other pathways using computational approaches (Bentley et al. 2008; Mac Gabhann and Popel 2008; Peirce 2008), and going forward a stronger integration of mathematical models and experimental readouts will result in a more complete understanding of VEGF signaling. VEGF receptors that bind ligands other than VEGF-A, such as VEGFR3/flt-4, are clearly important in vessel patterning (Lohela et al. 2009), but their role is much less understood. Finally, VEGF-A is important for arterial identity in some developmental contexts, and not all of the regulation of this aspect of VEGF signaling is well understood. As our knowledge of how VEGF patterns vessels is refined, it will be exciting to see how this knowledge contributes to development and refinement of the therapies sought by Judah Folkman and the field of vascular biology.

\section{ACKNOWLEDGMENTS}

I am honored to write a chapter on VEGF and its role in vessel patterning in a volume dedicated to Dr. Judah Folkman. The VEGF signaling pathway affects blood vessel formation and function in many ways, and Dr. Folkman was an incredible person who had an impact on the nascent field of vascular biology in many ways. I will leave the biographical details to others. However, I am one of the many scientists working in the field today whose career trajectory came under the influence of Dr. Folkman. As a postdoc, I made a transgenic mouse expressing a viral oncogene that resulted in the formation of hemangiomas, a somewhat unexpected result. Dr. Folkman was collaborating with Dr. Hanahan (whose group I was a part 
V.L. Bautch

of ), and I was able to show him my preliminary data. Dr. Folkman's excitement was infectious, and I soon found myself visiting his laboratory and embarking on a career in vascular biology as I set up my own independent research program. With hindsight, Dr. Folkman's philosophy that the field needed scientists with new tools and new approaches and his incredible energy to both recruit and support young scientists were both unique and forward-looking. His legacy and our mandate is to continue to seek out and support new investigators, with new approaches and ideas, to keep the field of vascular biology as exciting and innovative as it is today. I thank all past and current members of the Bautch laboratory, and numerous colleagues, for stimulating discussions. I also thank Dr. Sarah Taylor for the retinal vessel micrograph. I apologize to colleagues whose work was not cited as primary literature because of space constraints. This work is supported by grants from the National Institutes of Health (NIH) (R01s HL43174 and HL86465) to V.L.B.

\section{REFERENCES}

Ambler CA, Nowicki JL, Burke AC, Bautch VL. 2001. Assembly of trunk and limb blood vessels involves extensive migration and vasculogenesis of somite-derived angioblasts. Dev Biol 234: 352-364.

Ambler CA, Schmunk GA, Bautch VL. 2003. Stem cellderived endothelial cells/progenitors migrate and pattern in the embryo using the VEGF signaling pathway. Dev Biol 257: 205-219.

Ashe H, Briscoe J. 2006. The interpretation of morphogen gradients. Development 133: 385-394.

Bautch VL, James J. 2009. Neurovascular development: The beginning of a beautiful friendship. Cell Adh Migr 3: 199-204.

Bentley K, Gerhardt H, Bates P. 2008. Agent-based simulation of Notch-mediated tip cell selection in angiogenic sprout initialisation. J Theor Biol 250: 25-36.

Blum Y, Belting H-G, Ellertsdottir E, Herwig L, Lüders F, Affolter M. 2008. Complex cell rearrangements during intersegmental vessel sprouting and vessel fusion in the zebrafish embryo. Dev Biol 316: 312-322.

Bovolenta P, Esteve P, Ruiz J, Cisneros E, Lopez-Rios J. 2008 Beyond Wnt inhibition: New functions of secreted Frizzled-related proteins in development and disease. J Cell Sci 121: 737-746.

Carlson T, Hu H, Braren R, Kim Y, Wang R. 2008 Cell-autonomous requirement for $\beta 1$ integrin in endothelial cell adhesion, migration and survival during angiogenesis in mice. Development 135: 2193-2202.
Carmeliet P, Ferreira V, Breier G, Pollefeyt S, Kieckens L, Gertsenstein M, Fahrig M, Vandenhoeck A, Harpal K, Eberhardt C, et al. 1996. Abnormal blood vessel development and lethality in embryos lacking a single VEGF allele. Nature 380: 435-439.

Chappell JC, Taylor SM, Ferrara N, Bautch VL. 2009. Local guidance of emerging vessel sprouts requires soluble Flt-1. Dev Cell 17: 377-386.

Chen T, Luque A, Lee S, Anderson S, Segura T, Iruela-Arispe ML. 2010. Anchorage of VEGF to the extracellular matrix conveys differential signaling responses to endothelial cells. J Cell Biol 188: 595-609.

Cleaver O, Krieg PA. 1999. Molecular mechanisms of vascular development. In Heart development (ed. Harvey RP, Rosenthal N), pp. 221-252. Academic Press, San Diego.

Coultas L, Chawengsaksophak K, Rossant J. 2005. Endothelial cells and VEGF in vascular development. Nature 438: 937-945.

Culver JC, Dickinson ME. 2010. The effects of hemodynamic force on embryonic development. Microcirculation 17: $164-178$.

Damert A, Miquerol L, Gertsenstein M, Risau W, Nagy A. 2002. Insufficient VEGFA activity in yolk sac endoderm compromises haematopoietic and endothelial differentiation. Development 129: 1881-1892.

Daneman R, Agalliu D, Zhou L, Kuhnert F, Kuo C, Barres B. 2009. Wnt/ $\beta$-catenin signaling is required for CNS, but not non-CNS, angiogenesis. Proc Natl Acad Sci 106: 641-646.

Darland DC, Massingham LJ, Smith SR, Piek E, SaintGeniez M, D'Amore PA. 2003. Pericyte production of cell-associated VEGF is differentiation-dependent and is associated with endothelial survival. Dev Biol 264: 275-288.

da Silva R, Tavora B, Robinson S, Reynolds L, Szekeres C, Lamar J, Batista S, Kostourou V, Germain M, Reynolds A, et al. 2010. Endothelial $\alpha 3 \beta 1$-integrin represses pathological angiogenesis and sustains endothelial VEGF. Am J Pathol 177: 1534-1548.

Davis GE. 2010. The development of the vasculature and its extracellular matrix: A gradual process defined by sequential cellular and matrix remodeling events. Am J Physiol Heart Circ Physiol 299: H245-H247.

Dorrell M, Friedlander M. 2006. Mechanisms of endothelia cell guidance and vascular patterning in the developing mouse retina. Prog Retin Eye Res 25: 277-295.

Ellertsdottir E, Lenard A, Blum Y, Krudewig A, Herwig L, Affolter M, Belting H-G. 2010. Vascular morphogenesis in the zebrafish embryo. Dev Biol 341: 56-65.

Ferrara N. 2010. Binding to the extracellular matrix and proteolytic processing: Two key mechanisms regulating vascular endothelial growth factor action. Mol Biol Cell 21: 687-690.

Ferrara N, Carver-Moore K, Chen H, Dowd M, Lu L, O'Shea KS, Powell-Braxton L, Hillan KJ, Moore MW. 1996. Heterozygous embryonic lethality induced by targeted inactivation of the VEGF gene. Nature 380: 439-442.

Fong GH, Rossant J, Gertsenstein M, Breitman ML. 1995. Role of the Flt-1 receptor tyrosine kinase in regulating the assembly of vascular endothelium. Nature 376: $66-70$. 
Fruttiger M. 2007. Development of the retinal vasculature. Angiogenesis 10: 77-88.

Gaengel K, Genove G, Armulik A, Betsholtz C. 2009. Endothelial-mural cell signaling in vascular development and angiogenesis. Arterioscler Thromb Vasc Biol 29: 630-638.

Garriock R, Czeisler C, Ishii Y, Navetta A, Mikawa T. 2010. An anteroposterior wave of vascular inhibitor downregulation signals aortae fusion along the embryonic midline axis. Development 137: 3697-3706.

Gerhardt H, Golding M, Fruttiger M, Ruhrberg C, Lundkvist A, Abramsson A, Jeltsch M, Mitchell C, Alitalo K, Shima D, et al. 2003. VEGF guides angiogenic sprouting utilizing endothelial tip cell filopodia. J Cell Biol 161: $1163-1177$.

Ghabrial AS, Luschnig S, Metzstein M, Krasnow MA. 2003. Branching morphogenesis of the Drosophila tracheal system. Annu Rev Cell Dev Biol 19: 623-647.

Gu C, Rodriguez ER, Reimert DV, Shu T, Fritzsch B, Richards LJ, Kolodkin AL, Ginty DD. 2003. Neuropilin-1 conveys semaphorin and VEGF signaling during neural and cardiovascular development. Dev Cell 5: 45-57.

Hahn C, Schwartz MA. 2009. Mechanotransduction in vascular physiology and atherogenesis. Nat Rev Mol Cell Biol 10: $53-62$.

Hellstrom M, Phng L-K, Hofmann JJ, Wallgard E, Coultas L, Lindbrom P, Alva J, Nilsson A-K, Karlsson L, Gaiano N, et al. 2007. Dll4 signalling through Notch 1 regulates formation of tip cells during angiogenesis. Nature 445: $776-780$.

Hiratsuka S, Minowa O, Kuno J, Noda T, Shibuya M. 1998. Flt-1 lacking the tyrosine kinase domain is sufficient for normal development and angiogenesis in mice. Proc Natl Acad Sci 95: 9349-9354.

Hogan KA, Bautch VL. 2004. Blood vessel patterning at the embryonic midline. Curr Topics Dev Biol 62: 55-85.

Hogan KA, Ambler CA, Chapman DL, Bautch VL. 2004. The neural tube patterns vessels developmentally using the VEGF signaling pathway. Development 131: 15031513.

Holderfield MT, Hughes CCW. 2008. Crosstalk between vascular endothelial growth factor, Notch, and transforming growth factor- $\beta$ in vascular morphogenesis. Circ Res 102: 637-652.

Iruela-Arispe ML, Davis G. 2009. Cellular and molecular mechanisms of vascular lumen formation. Dev Cell 16 222-231.

Jakobsson L, Franco C, Bentley K, Collins R, Ponsioen B, Aspalter I, Rosewell I, Busse M, Thurston G, Medvinsky A, et al. 2010. Endothelial cells dynamically compete for the tip cell position during angiogenic sprouting. Nat Cell Biol 12: 943-953.

James J, Gewolb C, Bautch VL. 2009. Neurovascular development uses VEGF-A signaling to regulate blood vessel ingression into the neural tube. Development 136: 833-841.

Kamei M, Saunders WB, Bayless KJ, Dye L, Davis GE, Weinstein BM. 2006. Endothelial tubes assemble from intracellular vacuoles in vivo. Nature 442: 453-456.

Kappas NC, Zeng G, Chappell J, Kearney JB, Hazarika S, Kallianos K, Patterson C, Annex B, Bautch VL. 2008.
The VEGF receptor Flt-1 spatially modulates Flk-1 signaling and blood vessel branching. J Cell Biol 181: 847-858.

Kawasaki T, Kitsukawa T, Bekku Y, Matsuda Y, Sanbo M, Yagi T, Fujisawa H. 1999. A requirement for neuropilin-1 in embryonic vessel formation. Development 126: 4895 4902 .

Kearney JB, Ambler CA, Monaco KA, Johnson N, Rapoport RG, Bautch VL. 2002. Vascular endothelial growth factor receptor Flt-1 negatively regulates developmental blood vessel formation by modulating endothelial cell division. Blood 99: 2397-2407.

Kendall RL, Thomas KA. 1993. Inhibition of vascular endothelial cell growth factor activity by an endogenously encoded soluble receptor. Proc Natl Acad Sci 90: 10705-10709.

Kuhnert F, Mancuso M, Shamloo A, Wang H-T, Choksi V, Florek M, Su H, Fruttiger M, Young W, Heilshorn S, et al. 2010. Essential regulation of CNS angiogenesis by the orphan G protein-coupled receptor GPR124. Science 330: 985-989.

Kutcher ME, Herman IM. 2009. The pericyte: Cellular regulator of microvascular blood flow. Microvasc Res 7: 235-246.

Lee S, Jilani SM, Nikolova GV, Carpizo D, Iruela-Arispe ML. 2005. Processing of VEGF-A by matrix metalloproteinases regulates bioavailability and vascular patterning in tumors. J Cell Biol 169: 681-691.

Lee S, Chen T, Barber C, Jordan M, Murdock J, Desai S, Ferrara N, Nagy A, Roos K, Iruela-Arispe ML. 2007. Autocrine VEGF signaling is required for vascular homeostasis. Cell 130: 691-703.

Lobov IB, Renard RA, Papadopoulos N, Gale NW, Thurston G, Yancopoulos GD, Wiegand SJ. 2007. Delta-like ligand 4 (Dll4) is induced by VEGF as a negative regulator of angiogenic sprouting. Proc Natl Acad Sci 104: 3219-3224.

Lohela M, Bry M, Tammela T, Alitalo K. 2009. VEGFs and receptors involved in angiogenesis versus lymphangiogenesis. Curr Opin Cell Biol 21: 154-165.

Lubarsky B, Krasnow MA. 2003. Tube morphogenesis: Making and shaping biological tubes. Cell 112: 19-28.

Mac Gabhann F, Popel AS. 2008. Systems biology of vascular endothelial growth factors. Microcirculation 15: 715-738.

Mancuso M, Kuhnert F, Kuo C. 2008. Developmental angiogenesis of the central nervous system. Lymph Res Biol 6: 173-180.

McCue S, Noria S, Langille BL. 2004. Shear-induced reorganization of endothelial cell cytoskeleton and adhesion complexes. Trends Cardiovasc Med 14: 143-151.

McCue S, Dajnowiec D, Xu F, Zhang M, Jackson MR, Langille BL. 2006. Shear stress regulates forward and reverse planar cell polarity of vascular endothelium in vivo and in vitro. Circ Res 98: 939-946.

Mii Y, Taira M. 2009. Secreted Frizzled-related proteins enhance the diffusion of Wnt ligands and expand their signalling range. Development 136: 4083-4088.

Mukouyama YS, Shin D, Britsch S, Taniguchi M, Anderson DJ. 2002. Sensory nerves determine the pattern of arterial differentiation and blood vessel branching in the skin. Cell 109: 693-705. 
V.L. Bautch

Mukouyama YS, Gerber HP, Ferrara N, Gu C, Anderson DJ 2005. Peripheral nerve-derived VEGF promotes arterial differentiation via neuropilin 1-mediated positive feedback. Development 132: 941-952.

Olsson A-K, Dimberg A, Kreuger J, Claesson-Welsh L. 2006 VEGF receptor signaling-in control of vascular function. Nat Rev Mol Cell Biol 7: 359-371.

Paik JH, Skoura A, Chae SS, Cowan AE, Han DK, Proia RL, Hla T. 2004. Sphingosine 1-phosphate receptor regulation of N-cadherin mediates vascular stabilization. Genes Dev 18: 2392-2403.

Pardanaud L, Luton D, Prigent M, Bourcheix LM, Catala M, Dieterlen-Lievre F. 1996. Two distinct endothelial lineages in ontogeny, one of them related to hemopoiesis. Development 122: 1363-1371.

Park M, Lee ST. 1999. The fourth immunoglobulin-like loop in the extracellular domain of FLT-1, a VEGF receptor, includes a major heparin-binding site. Biochem Biophys Res Commun 264: 730-734.

Park JE, Keller GA, Ferrara N. 1993. The vascular endothelial growth factor (VEGF) isoforms: Differential deposition into the subepithelial extracellular matrix and bioactivity of extracellular matrix-bound VEGF. Mol Biol Cell 4: 1317-1326.

Park J, Chen H, Winer J, Houck K, Ferrara N. 1994. Placenta growth factor. Potentiation of vascular endothelia growth factor bioactivity, in vitro and in vivo, and high affinity binding to Flt-1 but not to Flk-1/KDR. J Biol Chem 269: 25646-25654.

Peirce SM. 2008. Computational and mathematical modeling of angiogenesis. Microcirculation 15: 739-751.

Piddini E, Vincent J-P. 2009. Interpretation of the wingless gradient requires signaling-induced self-inhibition. Cell 136: 296-307.

Reese DE, Hall CE, Mikawa T. 2004. Negative regulation of midline vascular development by the notochord. Dev Cell 6: 699-708.

Ribes V, Briscoe J. 2009. Establishing and interpreting graded Sonic hedgehog signaling during vertebrate neural tube patterning: The role of negative feedback. Cold Spring Harb Perspect Biol 1: a002014.

Risau W. 1997. Mechanisms of angiogenesis. Nature 386: 671-674.

Roberts DM, Kearney JB, Johnson JH, Rosenberg MP, Kumar R, Bautch VL. 2004. The vascular endothelial growth factor (VEGF) receptor Flt-1 (VEGFR-1) modulates Flk-1 (VEGFR-2) signaling during blood vessel formation. Am J Pathol 164: 1531-1535.

Ruhrberg C, Gerhardt H, Golding M, Watson R, Ioannidou S, Fujisawa H, Betsholtz C, Shima DT. 2002. Spatially restricted patterning cues provided by heparin-binding VEGF-A control blood vessel branching morphogenesis. Genes Dev 16: 2684-2698.

Samakovlis C, Hacohen N, Manning G, Sutherland D, Guillemin K, Krasnow MA. 1996. Development of the Drosophila tracheal system occurs by a series of morphologically distinct but genetically coupled branching events. Development 122: 1395-1407.

Scott A, Powner MB, Gandhi P, Clarkin C, Gutmann DH, Johnson RS, Ferrara N, Fruttiger M. 2010. Astrocytederived vascular endothelial growth factor stabilizes vessels in the developing retinal vasculature. PLoS ONE 5: e11863. doi: 10.1371/journal.pone.0011863.

Shalaby F, Rossant J, Yamaguchi TP, Gertsenstein M, Wu XF, Breitman ML, Schuh AC. 1995. Failure of blood-island formation and vasculogenesis in Flk-1-deficient mice. Nature 376: 62-66.

Siekmann AF, Covassin L, Lawson ND. 2008. Modulation of VEGF signalling output by the Notch pathway. Bioessays 30: $303-313$.

Simon MC, Keith B. 2008. The role of oxygen availability in embryonic development and stem cell function. Nat Rev Mol Cell Biol 9: 285-296.

Soker S, Takashima S, Miao HQ, Neufeld G, Klagsbrun M. 1998. Neuropilin-1 is expressed by endothelial and tumor cells as an isoform-specific receptor for vascular endothelial growth factor. Cell 92: 735-745.

Stalmans I, Ng YS, Rohan R, Fruttiger M, Bouche A, Yuce A, Fujisawa H, Hermans B, Shani M, Jansen S, et al. 2002. Arteriolar and venular patterning in retinas of mice selectively expressing VEGF isoforms. J Clin Invest 109: 327-336.

Stenman JM, Rajagopal J, Carroll TJ, Ishibashi M, McMahon J, McMahon AP. 2008. Canonical Wnt signaling regulates organ-specific assembly and differentiation of CNS vasculature. Science 322: 1247-1250.

Strilic B, Kucera T, Eglinger J, Hughes M, McNagny K, Tsukita S, Dejana E, Ferrara N, Lammert E. 2009. The molecular basis of vascular lumen formation in the developing mouse aorta. Dev Cell 17: 505-515.

Suchting S, Freitas C, le Noble F, Benedito R, Breant C, Duarte A, Eichmann A. 2007. The Notch ligand Deltalike 4 negatively regulates endothelial tip cell formation and vessel branching. Proc Natl Acad Sci 104: 3225-3230.

Tanjore H, Zeisberg E, Gerami-Naini B, Kalluri R. 2007. B1 integrin expression on endothelial cells is required for angiogenesis but not for vasculogenesis. Dev Dyn 237: 75-82.

Tzima E, Irani-Tehrani M, Kiosses WB, Dejana E, Schultz DA, Engelhardt B, Cao G, DeLisser H, Schwartz MA. 2005. A mechanosensory complex that mediates the endothelial cell response to fluid shear stress. Nature 437: 426-431.

Whitaker GB, Limberg BJ, Rosenbaum JS. 2001. Vascular endothelial growth factor receptor-2 and neuropilin-1 form a receptor complex that is responsible for the differential signaling potency of $\mathrm{VEGF}_{165}$ and $\mathrm{VEGF}_{121}$. J Biol Chem 276: 25520-25531.

Yan D, Lin X. 2009. Shaping morphogen gradients by proteoglycans. Cold Spring Harb Perspect Biol 1: a002493.

Zeeb M, Strilic B, Lammert E. 2010. Resolving cell-cell junctions: Lumen formation in blood vessels. Curr Opin Cell Biol 22: 626-632.

Zeng G, Taylor S, McColm J, Kappas NC, Kearney JB, Williams L, Hartnett M, Bautch VL. 2007. Orientation of endothelial cell division is regulated by VEGF signaling during blood vessel formation. Blood 109: 1345-1352.

Zovein A, Luque A, Turlo K, Hofmann JJ, Yee K, Becker M, Fassler R, Mellman I, Lane T, Iruela-Arispe ML. 2010. B1 integrin establishes endothelial polarity and arteriolar lumen formation via a Par3-dependent mechanism. Dev Cell 18: 39-51. 


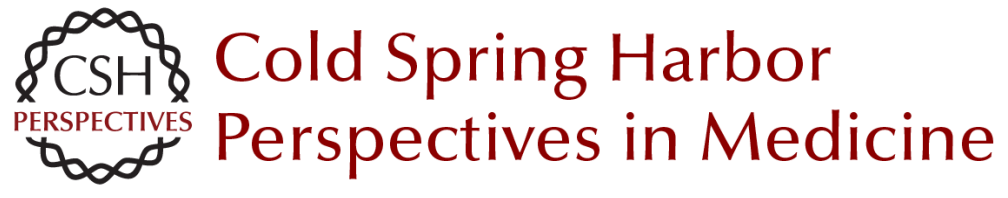

\section{VEGF-Directed Blood Vessel Patterning: From Cells to Organism}

Victoria L. Bautch

Cold Spring Harb Perspect Med 2012; doi: 10.1101/cshperspect.a006452 originally published online November 1, 2011

\section{Subject Collection Angiogenesis}

Extracellular Matrix Regulation of Vascular Morphogenesis, Maturation, and Stabilization George E. Davis and Scott S. Kemp

Endothelial Cell-Pericyte Interactions in the Pathogenesis of Cerebral Cavernous Malformations (CCMs) Wang Min and Jenny Huanjiao Zhou

Lymphatic Clearance and Pump Function Jerome W. Breslin

Platelets and (Lymph)angiogenesis Harvey G. Roweth and Elisabeth M. Battinelli

Modeling Brain Vasculature Immune Interactions In Vitro Ruth Lyck, Hideaki Nishihara, Sidar Aydin, et al.

Human Endothelial Colony-Forming Cells Juan M. Melero-Martin

\section{The Beauty and Complexity of Blood Vessel} Patterning

Victoria L. Bautch and Yoh-suke Mukouyama

Endothelialitis, Microischemia, and

Intussusceptive Angiogenesis in COVID-19 Steven J. Mentzer, Maximilian Ackermann and Danny Jonigk
Regulation of the Blood-Brain Barrier in Health and Disease Cara C. Rada, Kanako Yuki, Jie Ding, et al.

Targeting Angiogenesis via Resolution of Inflammation

Abigail G. Kelly and Dipak Panigrahy

Notch Signaling in the Vasculature: Angiogenesis and Angiocrine Functions

Sana S. Hasan and Andreas Fischer

Signal Transduction and Gene Regulation in the Endothelium

Michel V. Levesque and Timothy Hla

Buttons and Zippers: Endothelial Junctions in

Lymphatic Vessels

Peter Baluk and Donald M. McDonald

Endothelial Cell Fate Determination: A Top Notch Job in Vascular Decision-Making

L.A. Naiche, Stephanie R. Villa and Jan K. Kitajewski

Leukocyte Trafficking in Lymphatic Vessels Aline Bauer, Hazal Tatliadim and Cornelia Halin

Lymphatic Tissue and Organ Engineering for In Vitro Modeling and In Vivo Regeneration Anna M. Kolarzyk, Gigi Wong and Esak Lee

For additional articles in this collection, see http://perspectivesinmedicine.cshlp.org/cgi/collection/ 